\title{
Selection of antitumor displayed peptides for the specific delivery of the anticancer drug lactaptin
}

\author{
ANNA ANDREEVNA NEMUDRAYA ${ }^{1}$, ELENA VLADIMIROVNA KULIGINA ${ }^{1}$, \\ ALEXANDR ALEXEEVICH ILYICHEV ${ }^{2,3}$, ALEXANDR SERGEEVICH FOMIN ${ }^{1}$, \\ GRIGORY ALEXANDROVICH STEPANOV ${ }^{1}$, ANNA VALENTINOVNA SAVELYEVA ${ }^{1}$, \\ OLGA ALEXANDROVNA KOVAL ${ }^{1,3}$ and VLADIMIR ALEXANDROVICH RICHTER ${ }^{1}$ \\ ${ }^{1}$ Laboratory of Biotechnology, Institute of Chemical Biology and Fundamental Medicine,
} Siberian Branch of The Russian Academy of Sciences, 630090 Novosibirsk; ${ }^{2}$ Department of Bioengineering, State Research Center of Virology and Biotechnology VECTOR, 630559 Koltsovo;

${ }^{3}$ Department of Biology, Faculty of Natural Sciences, Novosibirsk State University, 630090 Novosibirsk, Russia

Received February 12, 2016; Accepted September 9, 2016

DOI: $10.3892 / 01.2016 .5266$

\begin{abstract}
It has been previously demonstrated that lactaptin, the proteolytic fragment of human milk protein $\kappa$-casein, induces the death of various cultured cancer cells. The recombinant analog of lactaptin, RL2, effectively induces the apoptosis of mouse hepatocarcinoma-1 (HA-1) tumor cells in vitro and suppress the growth of HA-1 tumors and metastases in vivo. The antitumor drug Lactaptin developed on the basis of RL2 has been successful in preclinical trials. Lactaptin shows its efficiency in relation to mouse and human cancer cells and tumors. However, Lactaptin, as with the majority of protein-based therapeutic drugs, is distributed evenly throughout the organism, which reduces its antitumor efficacy. To develop the targeted delivery of lactaptin, the present study selected tumor-specific peptides by screening a phage display peptide library in vivo on $\mathrm{A} / \mathrm{Sn}$ strain mice with subcutaneously transplanted HA-1 cells. Two genetic constructs were made for the production of recombinant fusion proteins composed of RL2 and the selected tumor-targeting peptide. In vitro experiments involving HA-1, MDA-MB-231 and MCF-7 cells cultures demonstrated that the fusion proteins induce apoptotic death in mouse and human tumor cells, as with RL2. The in vivo experiments involving the mouse HA-1 tumor model demonstrated that the tumor fluorescence intensity of the Cy5-fusion protein conjugates is higher than that of RL2-Cy5. As conjugation of the tumor-specific peptides to RL2 provided retention of RL2 in the tumor tissues,
\end{abstract}

Correspondence to: Ms. Anna Andreevna Nemudraya, Laboratory of Biotechnology, Institute of Chemical Biology and Fundamental Medicine, Siberian Branch of The Russian Academy of Sciences, 8 Lavrentiev Avenue, 630090 Novosibirsk, Russia

E-mail: ann.vaskova@gmail.com

Key words: tumor-specific peptides, lactaptin, fusion proteins, apoptosis, targeted delivery fusion proteins composed of lactaptin and peptides specific for human tumors are deemed promising to improve the antitumor efficiency of lactaptin.

\section{Introduction}

At present, the development of antitumor drugs on the basis of natural proteins and peptides that are able to induce apoptotic death in tumor cells and selectively suppress tumor growth is one of the most popular strategies in the search for novel therapeutics (1).

The protein lactaptin $(\sim 8.6 \mathrm{kDa})$, a proteolytic fragment of human $\kappa$-casein, with the ability to induce apoptotic death in tumor cells in vitro, was previously found in human breast milk $(2,3)$. A series of recombinant analogs of the natural peptide has been created $(4,5)$. It has been demonstrated that the lactaptin analog, RL2, induces apoptosis in mice and human tumor cells in vitro, and reduces the growth and metastasis of animal and human tumors in vivo $(6,7)$. The preclinical trials of the RL2-based therapeutic drug lactaptin have been successful $(7,8)$. The safety and antitumor efficacy of this drug have been demonstrated. However, lactaptin has several major drawbacks, as with all protein-based therapeutic drugs. Lactaptin is distributed evenly throughout the organism, which reduces the concentration of the drug in the tumor and, consequently, reduces the antitumor efficacy (8).

The present study reports a technique developed to improve the antitumor efficiency of the drug lactaptin using conjugates of tumor-specific peptides with RL2. One of the most common and convenient ways used to isolate tumor-specific peptides is by screening phage-display peptide libraries. Due to small size, low immunogenicity and relatively cheap chemical synthesis, tumor-specific peptides are considered as targeted delivery vehicles for therapeutic genes, cytokines, imaging agents, pro-apoptotic peptides and therapeutic drugs. Currently, a number are in clinical trials, as individual therapeutic agents or as agents for delivering drugs to the target organs and tissues (9). 
In the present study, tumor-specific peptides were selected by in vivo screening of a phage-display peptide library. Recombinant fusion proteins composed of the apoptosis-inducing protein RL2 and the selected peptides were synthesized. The cytotoxic properties of the fusion proteins were assessed using mouse and human tumor cells in culture, and the targeting properties were investigated using a mouse tumor model.

\section{Materials and methods}

Animals. The animals used in the present were 3-4-month-old A/Sn, C57B1/6, CBA, C3H strain mice (22-25 g) bred at the Institute of Cytology and Genetics, Siberian Branch of the Russian Academy of Sciences (SB RAS), Novosibirsk, Russia. The mice were kept under standard conditions and received standard food and water according to the approved study protocol (EEC directive 86/609/EEC). The protocol was approved by the Committee on the Ethics of Animal Experiments of the Administration of SB RAS (permit no. 8-2012), Novosibirsk, Russia. All the animal experiments were performed in compliance with the recommendations and requirements of the World Society for the Protection of Animals, and the European Convention for the Protection of Vertebrate Animals Used for Experimental and Other Scientific Purposes (Strasbourg, 1986).

Tumor strains and cell lines. The hepatocarcinoma-1 (HA-1), hepatocarcinoma-29 (HA-29), lung adenocarcinoma (LA), Krebs-2 carcinoma, Lewis lung carcinoma (LLC) and Ehrlich carcinoma strains were obtained from the Institute of Cytology and Genetics, SB RAS (Novosibirsk, Russia) and maintained in the ascitic form by weekly intraperitoneal transplantations using the following mouse strains: A/Sn (HA-1, LA), C57 Black (Krebs-2 carcinoma), CBA (LLC, HA-29) and C3H (Ehrlich carcinoma).

For in vivo experiments, ascites tumor cells were resuspended in saline to a final concentration of $10^{6}$ cells $/ \mathrm{ml}$ and $150 \mu \mathrm{l}$ of suspension was injected subcutaneously into the back of each mouse. After the tumor nodes grew to $0.7-0.9 \mathrm{~cm}$ in diameter, the animals were used in the study experiments.

The HA-1 cells were cultured in vitro in Dulbecco's modified Eagle's medium (DMEM; Sigma-Aldrich; Merck Millipore, Darmstadt, Germany) in the presence of $10 \%$ FBS (Gibco; Thermo Fisher Scientific, Inc., Waltham, MA, USA), 2 mM L-glutamine (Sigma-Aldrich; Merck Millipore), $250 \mathrm{mg} / \mathrm{ml}$ amphotericin B and $100 \mathrm{U} / \mathrm{ml}$ penicillin/streptomycin (Gibco; Thermo Fisher Scientific, Inc.) at $37^{\circ} \mathrm{C}$ in an atmosphere containing $5 \% \mathrm{CO}_{2}$.

The B16 melanoma, human breast adenocarcinoma MDA-MB-231 and MCF-7 cell lines were obtained from the Russian Collection of Cell Cultures (Institute of Cytology, RAS, Saint Petersburg, Russia). B16 melanoma cells were cultured in vitro in DMEM (Sigma-Aldrich; Merck Millipore) in the presence of $10 \%$ FBS (Gibco; Thermo Fisher Scientific, Inc.), 2 mM L-glutamine (Sigma-Aldrich; Merck Millipore), $250 \mathrm{mg} / \mathrm{ml}$ amphotericin B and $100 \mathrm{U} / \mathrm{ml}$ penicillin/streptomycin (Gibco; Thermo Fisher Scientific, Inc.) at $37^{\circ} \mathrm{C}$ in an atmosphere containing $5 \% \mathrm{CO}_{2}$. For the in vivo experiments, B16 melanoma cells were detached with $0.05 \%$ trypsin-EDTA, diluted to a final concentration of $10^{6} \mathrm{cells} / \mathrm{ml}$, and $150 \mu \mathrm{l}$ of the suspension was injected subcutaneously into the back of each mouse. After the tumor nodes grew to $0.5-0.6 \mathrm{~cm}$ in diameter, the animals were used in the study experiments.

MCF-7 cells were cultured in Iscove's modified Dulbecco's medium (Sigma-Aldrich; Merck Millipore) in the presence of $10 \%$ FBS, 2 mM L-glutamine, $250 \mathrm{mg} / \mathrm{ml}$ amphotericin B and $100 \mathrm{U} / \mathrm{ml}$ penicillin/streptomycin.

MDA-MB-231 cells were cultured in L15 in the presence of $10 \% \mathrm{FBS}, 2 \mathrm{mM}$ L-glutamine, $250 \mathrm{mg} / \mathrm{ml}$ amphotericin $\mathrm{B}$ and $100 \mathrm{U} / \mathrm{ml}$ penicillin/streptomycin at $37^{\circ} \mathrm{C}$ in an atmosphere containing $5 \% \mathrm{CO}_{2}$.

In vivo screening of the phage-display peptide library. A mouse with a subcutaneously transplanted HA-1 tumor was administered, via tail vein injection, $0.5 \mathrm{ml}$ of the phage-display peptide library $\left(2 \times 10^{9} \mathrm{PFU} / \mathrm{ml}\right.$; New England Biolabs, Inc., Ipswich, MA, USA) diluted in saline. The phage particles were allowed to circulate for $5 \mathrm{~min}$, after which the mouse was sedated with $2.5 \%$ Avertin solution at a dose of $0.2 \mathrm{ml}$ per $20 \mathrm{~g}$ of mouse body weight and the heart was perfused with $15 \mathrm{ml}$ saline to remove the unbound phage particles from the bloodstream. The tumor was removed, washed with phosphate-buffered saline (PBS) and homogenized in $1 \mathrm{ml}$ PBS containing $1 \mathrm{mM}$ of the protease inhibitor phenylmethylsulfonyl fluoride. The homogenate was centrifuged at $10,000 \times \mathrm{g}$ for $10 \mathrm{~min}$ at room temperature and then the supernatant was removed. Pellets were resuspended in $1 \mathrm{ml}$ blocking buffer and centrifuged at $10,000 \times \mathrm{g}$ for $10 \mathrm{~min}$ at room temperature and then the supernatant was removed. Pellets were resuspended in $1 \mathrm{ml}$ liquid E. coli ER2738 culture in lysogeny broth (optical density at $600 \mathrm{~nm}, 0.2-0.3$ ) to elute the bacteriophages that had bound to the tumor, and were incubated for $30 \mathrm{~min}$ at $37^{\circ} \mathrm{C}$. The eluate containing the phage particles was centrifuged at $10,000 \times \mathrm{g}$ for $10 \mathrm{~min}$ at room temperature. The suspension containing the phage particles was then amplified and the amplified phage particles were used in further rounds of selection.

Sequencing of phage DNA. After the third and fourth rounds of selection, the phage particles were titrated to obtain individual phage colonies, which were used for the isolation of DNA according to the protocol described by the manufacturer of the phage-display peptide library.

The single-stranded DNAs were used in Sanger sequencing (-96 gIII sequencing primer; 5'-CCC TCA TAG TTA GCG TAA CG-3'; New England Biolabs, Inc.). The sequencing reaction products were determined using an ABI 310 Genetic Analyzer (Applied Biosystems; Thermo Fisher Scientific, Inc.) (located at the Genomics Core Facility of SB RA, Novosibirsk, Russia). The nucleotide sequences of the inserts encoding the peptides were analyzed using MEGA 4.0 software (10).

Construction of plasmid DNA-expressing fusion proteins. The RL2 sequence was amplified from plasmid pGSDI/RL2 (4) using RL2_F and c1_RL2_R primers (Table I) with the following cycling conditions: $96^{\circ} \mathrm{C}$ for $5 \mathrm{~min}$, followed by 35 cycles of $96^{\circ} \mathrm{C}$ for $30 \mathrm{sec}, 66^{\circ} \mathrm{C}$ for $30 \mathrm{sec}, 72^{\circ} \mathrm{C}$ for $30 \mathrm{sec}$ and a final step of $72^{\circ} \mathrm{C}$ for $10 \mathrm{~min}$. At the first stage, to produce 
a fusion DNA sequence that encodes a selected peptide and RL2, the sequences that encode the peptides T1 and T2 and the region of overlap with the RL2 sequence were produced. The T1 sequence was amplified from ClonN1_target as a template using c1_RL2_F and c1_R primers with the following cycling conditions: $96^{\circ} \mathrm{C}$ for $5 \mathrm{~min}$, followed by 35 cycles of $96^{\circ} \mathrm{C}$ for $30 \mathrm{sec}, 65^{\circ} \mathrm{C}$ for $30 \mathrm{sec}, 72^{\circ} \mathrm{C}$ for $15 \mathrm{sec}$ and a final step of $72^{\circ} \mathrm{C}$ for $10 \mathrm{~min}$. The $\mathrm{T} 2$ sequence was amplified from ClonN2 target as a template using c2_RL2_F and c2_R primers with the following cycling conditions: $96^{\circ} \mathrm{C}$ for $5 \mathrm{~min}$, followed by 35 cycles of $96^{\circ} \mathrm{C}$ for $30 \mathrm{sec}, 65^{\circ} \mathrm{C}$ for $30 \mathrm{sec}, 72^{\circ} \mathrm{C}$ for $15 \mathrm{sec}$ and a final step of $72^{\circ} \mathrm{C}$ for $10 \mathrm{~min}$. At the second stage, the fusion T1_RL2 and T2_RL2 DNA sequences encoding the tumor-targeting peptide and RL2 were produced by polymerase chain reaction using the primer pairs c1_RL2_F, c1_RL2_R and c2_RL2_F, c1_RL2_R with the following cycling conditions: $96^{\circ} \mathrm{C}$ for $5 \mathrm{~min}$, followed by 35 cycles of $96^{\circ} \mathrm{C}$ for $30 \mathrm{sec}, 65^{\circ} \mathrm{C}$ for $35 \mathrm{sec}, 72^{\circ} \mathrm{C}$ for $35 \mathrm{sec}$ and a final step of $72^{\circ} \mathrm{C}$ for $10 \mathrm{~min}$. The amplicons produced at the first stage and the RL2 amplicon were used as templates. All the amplicons were separated on an agarose gel and extracted from the gel according to the manufacturer's instructions (Qiagen, Inc., Valencia, CA, USA).

DNA fragments encoding the fusion proteins T1_RL2 and T2_RL2 were inserted in plasmid pET-15b (Novagen; Merck Millipore) using the BamHI and NcoI restriction sites. The recombinant plasmids were cloned in E. coli TOP10 (Life Technologies; Thermo Fisher Scientific, Inc.).

The sequencing reaction was run using a BigDye Terminator Cycle Sequencing Ready Reaction kit (Applied Biosystems; Thermo Fisher Scientific, Inc.) and the reaction products were purified using a DyeEx Spin kit (Qiagen, Inc.) at the Genomics Core Facility of SB RAS. For the sequencing reaction, T7seq_F 5'-TAATACGACTCACTATAGGG-3' and T7seq_R 5'-GCTAGTTATTGCTCAGCGGT-3' were used as primers. The purified products were sequenced using an ABI 310 Genetic Analyzer (Applied Biosystems; Thermo Fisher Scientific, Inc.). The nucleotide sequences of interest were analyzed using MEGA 4.0 software.

The recombinant plasmids pET-15b_T1_RL and pET-15b_ T2_RL, which encode the fusion proteins T1_RL and T2_RL, respectively, were expressed in E. coli BL21 (DE3) (New England Biolabs, Inc., Ipswich, MA, USA).

MTT assay. The cytotoxic effects of the recombinant lactaptin analogs RL2,T1_RL and T2_RL on mouse and human tumor cells were investigated using the MTT assay (Sigma-Aldrich; Merck Millipore) according to a protocol described previously (6). The cells that had reached $30 \%$ confluence in a 96 -well plate were incubated for $48 \mathrm{~h}$ with protein preparations at various concentrations $(0.1-0.4 \mathrm{mg} / \mathrm{ml})$. After incubation, the supernatant was removed and $200 \mu \mathrm{l}$ MTT solution in RPMI 1640 medium $(0.5 \mathrm{mg} / \mathrm{ml})$ was added to each well and incubated for $4 \mathrm{~h}$ at $37^{\circ} \mathrm{C}$. The formazan crystals were dissolved in $150 \mu \mathrm{l}$ dimethyl sulfoxide. The optical density of the formazan solutions was measured using an Apollo LB912 photometer (Berthold Technologies, Oak Ridge, TN, USA) at a wavelength of $570 \mathrm{~nm}$. Cell viability was determined relative to the viability of the control cells $(100 \%) \pm$ standard deviation in three independent experiments.
Flow cytometry. The cells were incubated in 6-well culture plates and used in the experiments upon reaching 80-90\% confluence. The recombinant lactaptin analogs RL2, T1_RL and T2_RL $(0.6 \mathrm{mg} / \mathrm{ml})$ were added to culture medium and incubated for 18 and $24 \mathrm{~h}$. After incubation, the cells detached from the support were pooled with the cells detached by trypsinization (PBS, $0.5 \mathrm{mg} / \mathrm{ml}$ trypsin and $0.4 \mathrm{mg} / \mathrm{ml}$ EDTA). The pooled cells were precipitated by centrifugation at $400 \times \mathrm{x}$ for $5 \mathrm{~min}$ and washed with PBS. The exposure of phosphatidylserine (PS) at the outer surface of the cell membrane, and the activation of caspase- 3 and -7 were analyzed by flow cytofluorometry with fluorescein isothiocyanate Annexin V Apoptosis Detection kit I (BD Pharmingen, San Jose, CA, USA) and the Vybrant FAM Caspase-3 and -7 assay kit (Life Technologies; Thermo Fisher Scientific, Inc.) using a FACSCanto II cell analyzer (BD Biosciences, Franklin Lakes, NJ, USA).

Labeling of the recombinant lactaptin analogs with sulfo-Cy5. The recombinant lactaptin analogs RL2, T1_RL and T2_RL were isolated from $E$. coli and purified according to a protocol for the isolation of RL2 (5).

To label RL2, T1_RL and T2_RL with sulfo-Cy5, $0.2 \mathrm{mM}$ of each protein was incubated with $1.25 \mathrm{mM}$ of the fluorescent dye sulfo-Cy5 maleimide (Ex/Em=646/662; Lumiprobe $\mathrm{GmbH}$, Hannover, Germany) in Tris-HCl buffer (pH 5.5) for $4 \mathrm{~h}$ at $25^{\circ} \mathrm{C}$. The purification of the conjugates RL2-Cy5, T1_RL-Cy5 and T2_RL-Cy5 was performed by reversed-phase high-performance liquid chromatography on a C18 column using a Milichrom A-02 chromatograph (EcoNova, Novosibirsk, Russia) with acetonitrile-water as a mobile phase.

Retention of the RL2-Cy5, T1_RL-Cy5 and T2_RL-Cy5 conjugates in tumor tissue. Mice with subcutaneously transplanted HA-1 tumors were administered with $80 \mu \mathrm{g}$ of the conjugates RL2-Cy5, T1_RL-Cy5 and T2_RL-Cy5 in $200 \mu 1$ of PBS via tail vein injection. The conjugates were allowed to circulate for $10 \mathrm{~min}$, after which the tumors were removed and analyzed using a Kodak In Vivo FX Professional Imaging system. The excitation $(650 \mathrm{~nm})$ and emission $(700 \mathrm{~nm})$ filters were used to detect the fluorescence of Cy5. The fluorescence intensity was recorded as total photons per second per square centimeter (mean \pm standard deviation).

Statistical analysis. The data from the mouse experiments were statistically processed using one-way analysis of variance. Post-hoc testing was performed using Fisher's least significant differences (LSD). $\mathrm{P}<0.05$ was considered to indicate a statistically significant difference. STATISTICA v10.0 was used to perform the statistical analyses (StatSoft, Inc., Tulsa, OK, USA).

\section{Results}

In vivo screening of the phage-display peptide library. To isolate tumor-specific peptides, four rounds of selection were performed in vivo on $\mathrm{A} / \mathrm{Sn}$ strain mice with subcutaneously transplanted HA-1 tumors. After the third round of selection, 37 displayed sequences were identified and analyzed, and after the fourth round, 38 sequences were identified (Table II). 
Table I. Sequences of the oligonucleotides used in the construction of plasmid DNA-expressing fusion proteins.

\begin{tabular}{|c|c|}
\hline Oligonucleotide & Sequence $\left(5^{\prime} \rightarrow 3^{\prime}\right)$ \\
\hline L2_F & $\begin{array}{l}\text { AACCAGAAACAACCAGCATGCCAT } \\
\text { GAGAATGAT }\end{array}$ \\
\hline c1_RL2_R & $\begin{array}{l}\text { CATCATGGATCCTTAGTGATGGTGA } \\
\text { TGGTGATGTGATCCGCCGATGGT }\end{array}$ \\
\hline c1_RL2_F & $\begin{array}{l}\text { CATCATCCATGGGTTTGCATACTTC } \\
\text { GGCT }\end{array}$ \\
\hline c1_R & $\begin{array}{l}\text { CTGGTTGTTTCTGGTTCGAACCTCA } \\
\text { CCAGCAA }\end{array}$ \\
\hline ClonN1_target & $\begin{array}{l}\text { GGTTTGCATACTTCGGCTACTAATC } \\
\text { TGTATTTGCATGGTGGAGGTTCG }\end{array}$ \\
\hline c2_RL2_F & $\begin{array}{l}\text { CATCATCCATGGGCAGTGGTGTGTA } \\
\text { TAAGGTT }\end{array}$ \\
\hline c2_R & $\begin{array}{l}\text { TGGTTGTTTCTGGTTCGAACCTCCA } \\
\text { CCATGCT }\end{array}$ \\
\hline ClonN2_target & $\begin{array}{l}\text { AGTGGTGTGTATAAGGTTGCGTATG } \\
\text { ATTGGCAGCATGGTGGAGGTTCG }\end{array}$ \\
\hline
\end{tabular}

After the third round of in vivo selection on the HA-1 tumor model, the most frequent outputs were two displayed peptides, GLHTSATNLYLH (35.1\%) and SGVYKVAYDWQH (21.6\%). After the fourth round of in vivo selection, the frequency of the peptide GLHTSATNLYLH increased to $63.2 \%$, while that of the peptide SGVYKVAYDWQH remained unchanged.

As the displayed peptides GLHTSATNLYLH and SGVYKVAYDWQH occurred with the highest frequency in the in vivo experiments, those clones were used in further experiments.

In vivo specificity of the selected peptides to various mouse tumors. The ability of the displayed peptides GLHTSATNLYLH and SGVYKVAYDWQH to specifically bind to tumors in vivo was studied using HA-1, LA, B16 melanoma, Krebs-2 carcinoma, LLC, Ehrlich carcinoma and HA-29 tumors.

The individual phage clones displaying the selected peptides were administered to mice via tail vein injection. At $24 \mathrm{~h}$ post-administration, the tumor and the control organs (lung and liver) were examined for bacteriophages (PFU/mg tissue) by titrating on E. coli ER2738 culture cells (Fig. 1).

As shown from the data presented in Fig. 1, the selected peptides were significantly bound not only to the selection-specific tumor (HA-1), but also to other tumors (LA, B16 melanoma, Krebs- 2 carcinoma and LLC) $(\mathrm{P}<0.05)$. The highest amount of binding was for HA-1. At $24 \mathrm{~h}$ post-intravenous administration, the concentration of the control bacteriophage (without any displayed peptide) in the tumor remained relatively low (just two or three times the value in the liver and lung). This is consistent with literature data, according to which the wild-type bacteriophage has a low capacity for retention and accumulation in tumor tissue, as the vascular system in tumors is poorly organized (11).

Construction of fusion proteins with the selected peptides and RL2. Two genetic constructs, pET-15b_T1_RL and
Table II. Sequences and frequencies of displayed peptides isolated after the third and fourth rounds of in vivo selection using $\mathrm{A} / \mathrm{Sn}$ strain mice with subcutaneously transplanted HA-1 tumors.

\begin{tabular}{|c|c|}
\hline Peptide sequence & Frequency, $\%$ \\
\hline III round & 35.1 \\
\hline GLHTSATNLYLH $^{\mathrm{a}}$ & 21.6 \\
\hline SGVYKVAYDWQH ${ }^{\mathrm{a}}$ & 5.4 \\
\hline GSAPLLTVDTSK & 2.7 \\
\hline GRIEPHRLFQGA & 2.7 \\
\hline QFDYMRPANDTH & 2.7 \\
\hline LGSSHGHGASHQ & 2.7 \\
\hline DRWVARDPASIF & 2.7 \\
\hline YASDLQPLTQFI & 2.7 \\
\hline STSDYTQWTSYA & 2.7 \\
\hline YGHGLNQAELRQ & 2.7 \\
\hline GDGNSVLKPGNW & 2.7 \\
\hline GTGLVTLPRLTV & 2.7 \\
\hline DLGRASWNPFFS & 2.7 \\
\hline ANLTRWPHNVST & 2.7 \\
\hline DVSTYKTNAQNS & 2.7 \\
\hline NWSHNVRLNYTY & 2.7 \\
\hline NTNYVTWSPSSR & 35.1 \\
\hline \multicolumn{2}{|l|}{ IV round } \\
\hline GLHTSATNLYLH ${ }^{a}$ & 63.2 \\
\hline SGVYKVAYDWQH ${ }^{\mathrm{a}}$ & 21.1 \\
\hline MHPNAGHGSLMR & 5.3 \\
\hline SFKIPYHYDSGQ & 2.6 \\
\hline DRWVARDPASIF ${ }^{\mathrm{a}}$ & 2.6 \\
\hline ENLMHADKNFRS & 2.6 \\
\hline LQSTSPAYTHRM & 2.6 \\
\hline GDGNSVLKPGNW & 2.6 \\
\hline
\end{tabular}

apeptides discussed in the main text.

pET-15b_T2_RL, were made for the production of recombinant fusion proteins composed of RL2 and the selected tumor-targeting peptides that deliver RL2.

The sequence encoding the fusion protein was constructed so that the synthesis product appears as a polypeptide with the tumor-targeting peptide fused to the N-terminus (with methionine as the first amino acid) and RL2 fused to the C-terminus. The targeting peptide and RL2 are spaced by a glycine linker, which provides for the flexibility of the peptide (Fig. 2).

To produce the desired recombinant proteins, two E. coli expression systems, BL21 (DE3)/pET-15b_T1_RL and BL21 (DE3)/pET-15b_T2_RL, were developed.

In vitro cytotoxic activity of $R L 2, T 1_{-} R L$ and $T 2 \_R L$. A comparative analysis of the effects of RL2 and the recombinant fusion proteins T1_RL and T2_RL on tumor cell viability was performed using HA-1, MDA-MB-231 and MCF-7 cell cultures. Changes in cell viability were assessed using the MTT assay. 


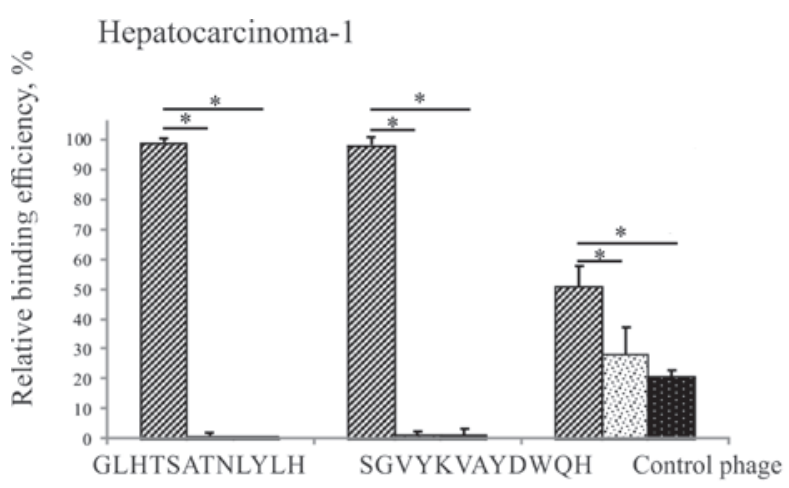

B16 melanoma

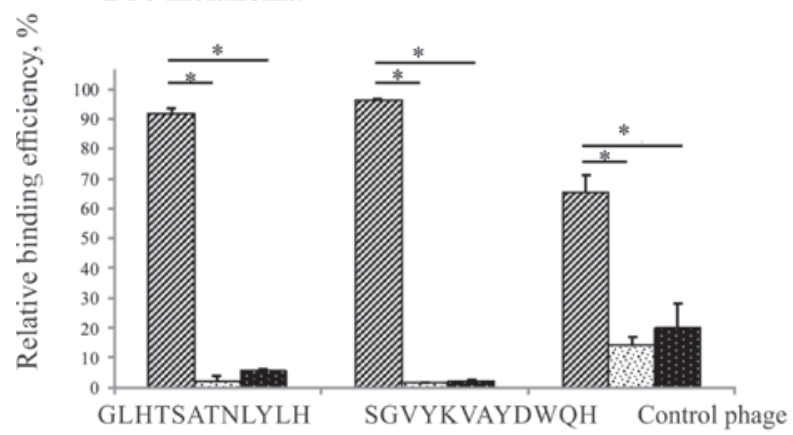

Lewis lung carcinoma
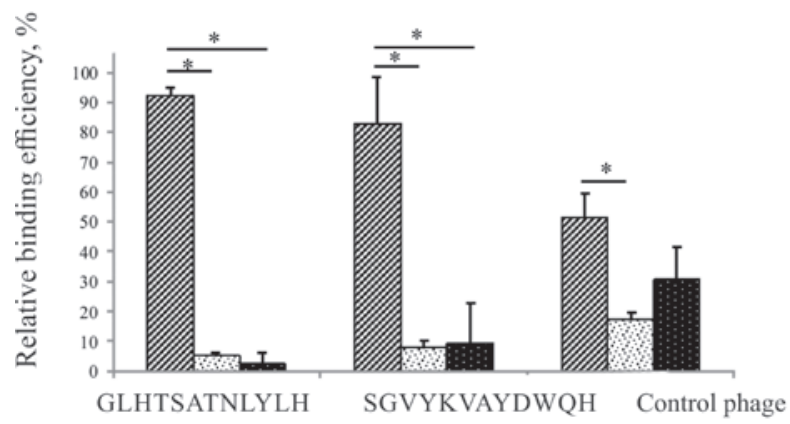

Lung carcinoma
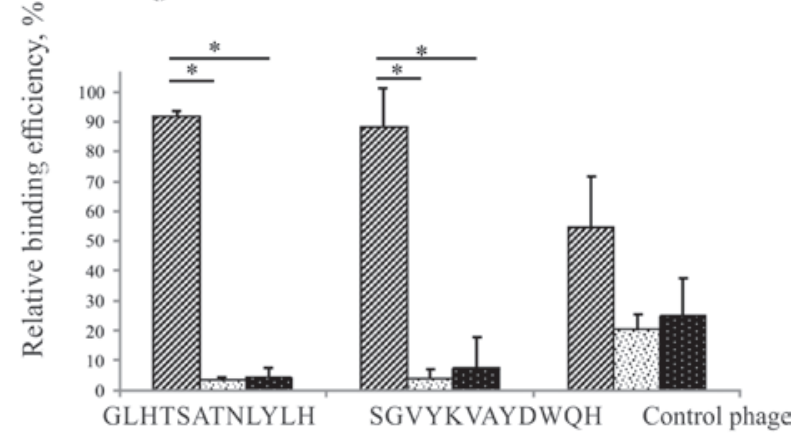

Krebs-2 carcinoma



Figure 1. Relative binding (\% of total) of the bacteriophages displaying the peptides GLHTSATNLYLH and SGVYKVAYDWQH, and the control bacteriophage (displaying neither) to different types of tumors and the control organs (liver and lung). Data are presented as the mean \pm standard deviation. ${ }^{*} \mathrm{P}<0.05$ was considered to indicate a statistically significant difference.

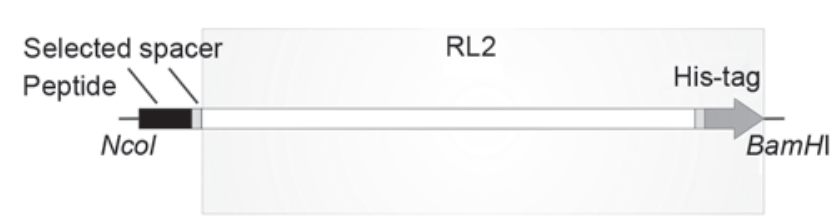

Figure 2. A schematic of the DNA sequence encoding a fusion protein.

It was demonstrated that T1_RL and T2_RL reduce the viability of HA-1, MDA-MB-231 and MCF-7 cells in a dose-dependent manner, while the cytotoxic activity of the fusion proteins was practically the same as that of RL2 (Fig. 3).

As is known, no wild-type bacteriophage can infect eukaryotic cells or produce a cytotoxic effect on them (11). Additionally, the present study demonstrated that the incubation of MDA-MB-231 and MCF-7 tumor cells with the bacteriophages that display the peptides GLHTSATNLYLH and SGVYKVAYDWQH has no effect on cell viability (data not shown).
Data obtained strongly suggest that the cytotoxic activity of the fusion proteins is solely due to RL2, while the tumor-targeting peptide fused to the N-terminus of RL2 has no effect on its cytotoxic properties.

The cytotoxic activity of RL2 in relation to tumor cells is due to its ability to induce apoptosis in these cells $(6,7)$. The current study assessed the ability of the fusion proteins T1_RL and T2_RL to induce apoptosis in MDA-MB-231 cells by cytometry. After the incubation of MDA-MB-231 cells with RL2 and T2_RL for $18 \mathrm{~h}$, the population of apoptotic MDA-MB-231 cells increased to 27.9 and $35.6 \%$, respectively, compared with the population of control cells (16.1\%). The incubation of MDA-MB-231 cells with T1_RL for $18 \mathrm{~h}$ led to no change in the number of apoptotic cells as compared to that in the control cells (Fig. 4); however, incubation with T1_RL for a longer time, $24 \mathrm{~h}$, led to an increase in the number of apoptotic cells (data not shown).

A key role in apoptosis is played by specific proteins, the caspases (cysteine proteases) (12). As is known, RL2-induced apoptosis is accompanied by the activation of 
HA-1



MDA-MB-231

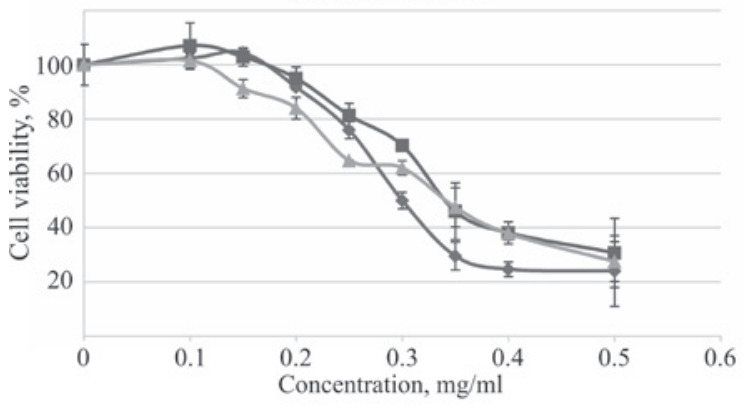

MCF-7

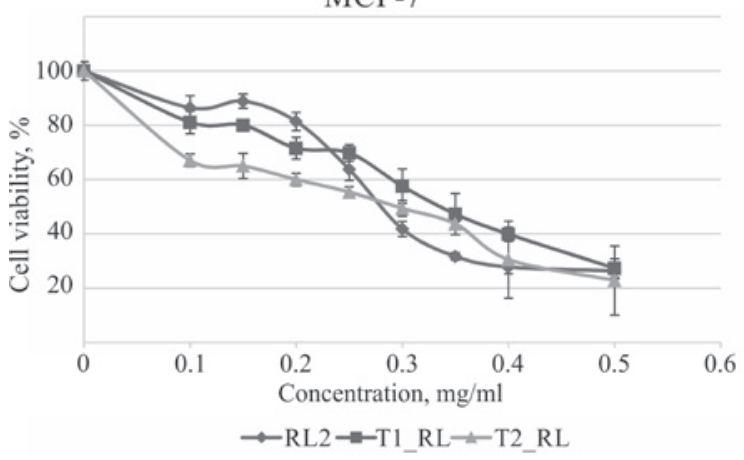

Figure 3. Changes in the viability of HA-1, MDA-MB-231 and MCF-7 tumor cells induced by RL2, T1_RL and T2_RL. Tumor cell viability was determined relative to the viability of the control cells (incubated without the proteins) (mean \pm standard deviation) in three independent experiments.

effector caspase-3 and -7, and mitochondrial transmembrane potential dissipation $(7,13)$. Activation of caspase-3 and -7 in MDA-MB-231 cells by the recombinant proteins RL2, T1_RL and T2_RL was analyzed by cytofluorometry in the present study. As shown in the data presented in Fig. 4B, following incubation with RL2, the percentage of cells expressing active forms of caspase-3 and -7 increased to 19.7, to $24.8 \%$ after incubation with T1_RL and to $18.3 \%$ after incubation with T2_RL, while the increase in the control cells was only $7.7 \%$.

Retention of the RL2-Cy5,T1_RL-Cy5 and T2_RL-Cy5 conjugates in tumor tissue. The accumulation of the recombinant fusion proteins in tumor tissue was assessed using the mouse HA-1 tumor model. Mice with subcutaneously transplanted tumors were administered with the conjugates RL2-Cy5, T1_RL-Cy5 and T2_RL-Cy5 via tail vein injection. The Cy5-labeled conjugates were allowed to circulate for $10 \mathrm{~min}$, after which the tumors were removed. The intensity of the fluorescent signal from the tumors was measured using a Kodak In Vivo FX Professional Imaging system (Fig. 5).
As observed in Fig. 5, subsequent to circulation of the recombinant proteins in the bloodstream for $10 \mathrm{~min}$, the strongest fluorescent signal from the tumor was for T1_RL; its intensity was $5.08 \pm 1.15$ times as high as that of the signal from the tumor with RL2 $(\mathrm{P}<0.05)$. The intensity of the fluorescent signal from the tumor with T2_RL was only $2.81 \pm 1.48(\mathrm{P}<0.05)$ times as high as that the signal from the tumor with RL2.

\section{Discussion}

One of the most promising ways to improve the efficiency of antitumor drugs is the targeted delivery of these drugs to tumor cells.

To this end, tumor-targeting peptides of a small size (not longer than 50 amino acid residues) are often used (14,15). A quick and convenient way to isolate peptides such as these is by the screening of phage-display peptide libraries, which is performing in vitro using tumor cell cultures and in vivo using animal models (16). The two screening systems each have their advantages. In vitro screening allows for the isolation of tumor-targeting peptides that are highly specific for cell surface receptors, without even knowing what a particular target may be. In vivo screening allows for the isolation of peptides that are specific for tumor tissue in its natural microenvironment. Moreover, peptides that interact with non-target molecules, such as ubiquitous cell surface protein and plasma proteins, or those that do not survive the degradative environment of the vascular system are depleted from the phage population (17). In addition to those characteristics that make tumor cells and tumor endothelial cells distinct from normal cells, physical differences exist between tumor and normal tissue (temperature change, low oxygen (hypoxia) and reduction in $\mathrm{pH}$ ) and they affect in vivo selection outputs (18-20).

It was previously shown that HA-1 was highly sensitive to RL2 treatment in vitro and in vivo (5). Therefore, a targeted delivery of the drug lactaptin was primarily developed using the mouse HA-1 tumor model in the present study.

To obtain HA-1 specific peptides, a selection method was applied using phage peptide libraries. Two displayed peptides, GLHTSATNLYLH and SGVYKVAYDWQH, occurred with the highest frequency after the fourth round of in vivo selection performed on A/Sn mice with HA-1 tumors. The selected phage clones were studied for the ability to bind different types of tumors in vivo at $24 \mathrm{~h}$ post-intravenous administration. The affinity of the selected displayed peptides was shown not only to the selection-specific tumor (HA-1), but also to other tumors (LA, B16 melanoma, Krebs-2 carcinoma and LLC). It appears that the peptides GLHTSATNLYLH and SGVYKVAYDWQH are specific for the targets that are typical of different types of tumor cells.

According to literature data, tumor cells possess numerous quantitative and/or qualitative properties that make them distinct from non-tumor cells and that the majority of tumor cell types have in common. For example, the receptors of growth and proliferation factors, including epidermal growth factor receptors, transferrin receptors and folic acid receptors, are often overexpressed on tumor cells, which provides for uncontrolled cell proliferation and promotes metastasis (18). Furthermore, markers exist that are typical of particular 
A
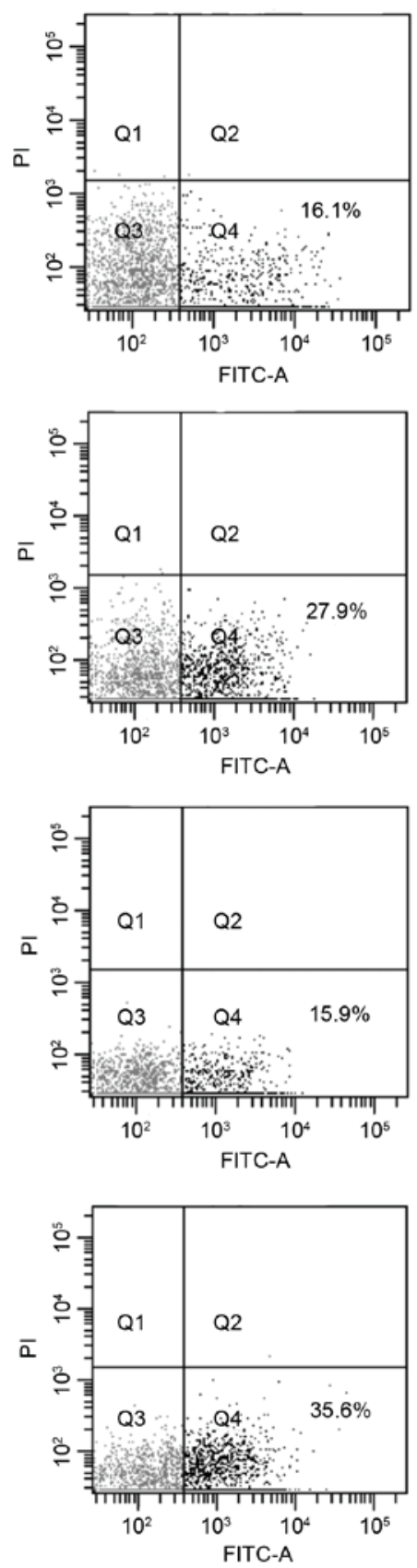
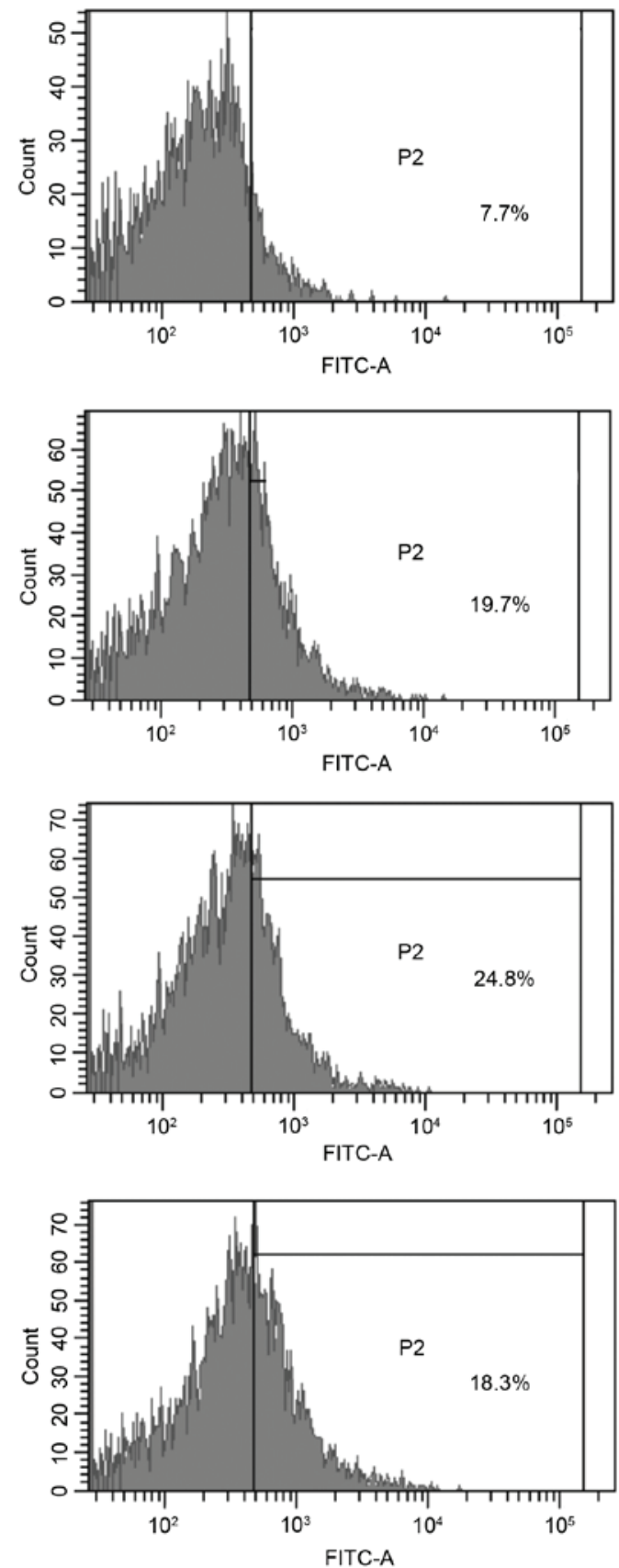

Figure 4. Results of flow cytofluorometry with MDA-MB-231 cells after incubation with RL2, T1_RL and T2_RL (0.6 mg/ml) for $18 \mathrm{~h}$. (A) Staining with FITC-labeled Annexin/PI cells. Q1 (FITC//PI $\left.{ }^{+}\right)$, cell debris; Q2 (FITC $\left.{ }^{+} / \mathrm{PI}^{+}\right)$, necrotic cells or late apoptotic cells; Q3 (FITC-PI $)$, viable cells; and Q4 $\left(\mathrm{FITC}^{+} / \mathrm{PI}\right)^{-}$, apoptotic cells. (B) FITC-positive cells expressing active forms of caspase-3 and -7. FITC, fluorescein isothiocyanate; PI, propidium iodide.

groups of cell lines. For example, enhanced expression of the matrix metalloproteinase- 2 and aminopeptidase $\mathrm{N}$ receptors is observed on breast cancer cells $(20,21)$, while enhanced expression of platelet-derived growth factor receptor- $\beta$ is observed on pancreas tumor cells (20).

It is also known that tumor growth is accompanied by active angiogenesis, which, in a healthy adult, can only be the case if damaged tissues are undergoing regeneration. Angiogenesis activation may, for example, occur when the level of the expression of vascular endothelial growth factors is increasing or when the level of the expression of receptors for the $\alpha_{v} \beta_{3} / 5$ integrins is increased (19).
RL2

T1 RL

T2 RL
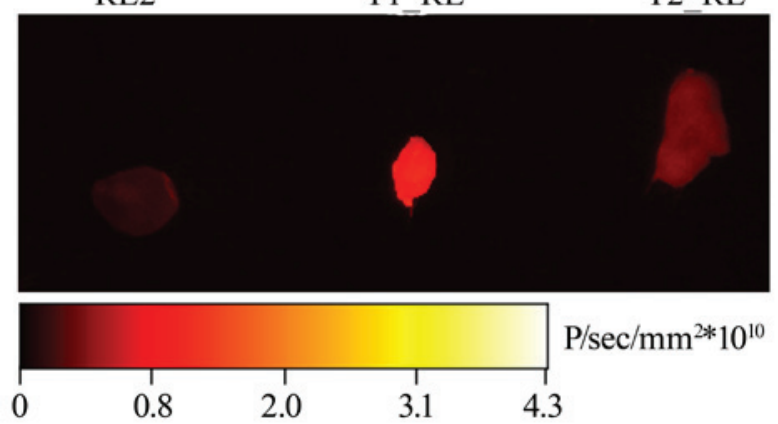

Figure 5. Macroscopic fluorescent images of tumors. 
Additionally, incomplete poorly organized vasculature that associates with tumor growth results in hypoxic zones and a reduction in nutrient availability within the tumor tissue. The ability to adapt to hypoxic conditions is crucial to tumor growth and survival, and occurs through the hypoxia inducible factor signaling pathway, which affects the expression of $>1,000$ genes (22).

As there was no significant binding of the displayed peptides to Ehrlich or HA-29 tumors in the present study (data not shown), these tumors do not appear to possess the molecular structures or microenvironment for which selection was run. Thus, peptides that were able to specifically deliver the associated cargo to mouse tumors in vivo were selected.

Genetic constructs that provide for the production of the fusion proteins composed of the selected peptides and RL2 were created and the recombinant fusion proteins, T1_RL and T2_RL, were prepared. With the genetic constructs that provide for the synthesis of the fusion proteins in producing strains, such stages towards end products as the production, isolation and purification of each component (lactaptin and the tumor-targeting peptide) separately, as well as the final stage of conjugating two protein molecules, are unnecessary.

Fusion of a tumor-targeting peptide to RL2 may lead to a considerable accumulation of this cytotoxic agent in tumor tissue and improve the antitumor efficiency of the drug. Admittedly, it should be ensured that fusion of the tumor-targeting peptide to the N-terminus of RL2 does not affect its cytotoxic activity in relation to tumor cells. The in vitro experiments of the present study demonstrated that RL2 and the fusion proteins T1_RL and T2_RL reduce the viability of HA-1 cancer cells in the same dose-dependent manner.

The antitumor drug lactaptin, developed on the basis of the recombinant lactaptin analog RL2, has been successful in preclinical trials. Lactaptin shows its highest efficiency in relation to human breast cancers, including triple-negative cancer [estrogen receptor $(\mathrm{ER})^{-/}$/progesterone receptor $(\mathrm{PR}) /$ /human epidermal growth factor receptor 2 (HER2)-]. Triple-negative cancer is often more aggressive than any other breast cancer and is unique in that the therapeutic targets that are typical of this disease, namely ER, PR and HER2/neu, are not there $(23,24)$. Therefore, in the present study, the cytotoxic activity was assessed not only in relation to mouse tumor HA-1 cells, but also human breast cancers. The data confirmed that RL2 and the fusion proteins T1_RL and T2_RL have identical cytotoxic properties and mechanisms of cell death induction.

Based on pharmacokinetic data, lactaptin is quite evenly distributed throughout the organism, with a certain degree of preference for the liver and kidneys. The half-life of lactaptin is $15.6 \mathrm{~min}$ (8). The present in vivo experiments involving the mouse HA-1 tumor model demonstrated that tumor concentrations of the conjugates T1_RL-Cy5 and T2_RL-Cy5 after 10 min of circulation are higher than that of RL2-Cy5, with fluorescence intensities of $5.08 \pm 1.15$ and $2.81 \pm 1.48$, respectively.

Several factors may account for the slight difference in fluorescence intensity that was observed between the tumors. Each phage particle in the library displays five copies of a specific peptide as part of coat protein pIII, which provides for the multivalent binding and a high avidity of the particle, but reduces affinity of the peptide for the target (25). A single copy of the selected peptide within the fusion proteins may have not been sufficient for efficient binding due to a decreased affinity of the molecule for the receptor as a whole. Additionally, the peptides displayed on the surface of the phage particle in five copies can interact with each other to form dimers or multimers, thus providing for specific binding. With the introduction of a pool of separate peptides, chances of this happening decrease.

The study by Ahn et al (26) is notable as it demonstrated that the tumor concentration of fusion proteins with the tumor-targeting RGD peptide specific for the $\alpha_{v} \beta_{3}$ integrin increases with increase in circulation time.

Thus, in the present study, a technique to improve the antitumor efficiency of the drug lactaptin was developed by conjugating this drug to a tumor-specific targeting peptide. Fusion proteins composed of lactaptin and peptides specific for the molecular structures of human tumors (in particular, breast tumors) are deemed promising.

\section{Acknowledgements}

The present study was supported by The Ministry of Education and Science of the Russian Federation, Federal Targeted Program 'R\&D in Priority Areas of Russian S\&T Development', contract 14.607.21.0063 (project unique identifier RFMEFI60714X0063).

\section{References}

1. Millimouno FM, Dong J, Yang L, Li J and Li X: Targeting apoptosis pathways in cancer and perspectives with natural compounds from mother nature. Cancer Prev Res (Phila) 7: 1081-1107, 2014.

2. Nekipelaya VV, Semenov DV, Potapenko MO, Kuligina EV, $\mathrm{Kit} \mathrm{Yu}$, Romanova IV and Richter VA: Lactaptin is a human milk protein inducing apoptosis of MCF-7 adenocarcinoma cells. Dokl Biochem Biophys 419: 58-61, 2008.

3. Vlassov VV, Richter VA, Semenov DV, Nekipelaya VV, Kuligina EV and Potapenko MO: Peptide inducing apoptotic death of human cancer cells. Patent RF N 2317304, 2008.

4. Tikunova NV, Semenov DV, Babkina IN, Kuligina EV Koval OA, et al: Recombinant plasmid DNA pFK2, providing synthesis of the recombinant peptide which is the analog of human kappa-casein and recombinant peptide-the analog of human kappa-casein fragment, with the apoptotic activity against human tumor cells. Patent RF N 2401307, 2010.

5. Semenov DV, Fomin AS, Kuligina EV, Koval OA, Matveeva VA, Babkina IN, Tikunova NV and Richter VA: Recombinant analogs of a novel milk pro-apoptotic peptide, lactaptin, and their effect on cultured human cells. Protein J 29: 174-180, 2010.

6. Koval OA, Fomin AS, Kaledin VI, Semenov DV, Potapenko MO, Kuligina EV, Nikolin VP, Nikitenko EV and Richter VA: A novel pro-apoptotic effector lactaptin inhibits tumor growth in mice models. Biochimie 94: 2467-2474, 2012.

7. Koval OA, Tkachenko AV, Fomin AS, Semenov DV, Nushtaeva AA, Kuligina EV, Zavjalov EL and Richter VA: Lactaptin induces p53-independent cell death associated with features of apoptosis and autophagy and delays growth of breast cancer cells in mouse xenografts. PLoS One 9: e93921, 2014.

8. Bondarenko DA, Richter VA, Kuligina EV, Koval OA, Fomin AS, et al: Toxicity studies and pharmacokinetics of Lactaptin. Russian Journal of Biopharmaceuticals 7: 40-47, 2015.

9. Nemudraya AA, Richter VA and Kuligina EV: Phage peptide libraries as a source of targeting ligands. Acta Naturae 8: 48-57, 2016.

10. Tamura K, Dudley J, Nei M and Kumar S: MEGA4: Molecular evolutionary genetics analysis (MEGA) software version 4.0. Mol Biol Evol 24: 1596-1599, 2007.

11. Bakhshinejad B and Sadeghizadeh M: Bacteriophages as vehicles for gene delivery into mammalian cells: Prospects and problems. Expert Opin Drug Deliv 11: 1561-1574, 2014. 
12. Galluzzi L, Vitale I, Abrams JM, Alnemri ES, Baehrecke EH, Blagosklonny MV, Dawson TM, Dawson VL, El-Deiry WS, Fulda S, et al: Molecular definitions of cell death subroutines: Recommendations of the Nomenclature Committee on Cell Death 2012. Cell Death Differ 19: 107-120, 2012.

13. Fomin AS, Koval' OA, Semenov DV, Potapenko MO, Kuligina EV, Kit IuIa and Rikhter VA: The Analysis of biochemical markers of MCF-7 cells apoptosis induced by recombinant analog of lactaptin. Bioorg Khim 38: 92-98, 2012.

14. Svensen N, Walton JG and Bradley M: Peptides for cell-selective drug delivery. Trends Pharmacol Sci 33: 186-192, 2012.

15. Venditto VJ and Szoka FC Jr: Cancer nanomedicines: So many papers and so few drugs! Adv Drug Deliv Rev 65: 80-88, 2013.

16. Hamzeh-Mivehroud M, Alizadeh AA, Morris MB, Church WB and Dastmalchi S: Phage display as a technology delivering on the promise of peptide drug discovery. Drug Discov Today 18 1144-1157, 2013

17. Krumpe LR and Mori T: The use of phage-displayed peptide libraries to develop tumor-targeting drugs. Int J Pept Res Ther 12: 79-91, 2006.

18. Wicki A, Witzigmann D, Balasubramanian V and Huwyler J Nanomedicine in cancer therapy: Challenges, opportunities, and clinical applications. J Control Release 200: 138-157, 2015.
19. Ruoslahti E: Specialization of tumour vasculature. Nat Rev Cancer 2: 83-90, 2002.

20. Li ZJ and Cho $\mathrm{CH}$ : Peptides as targeting probes against tumor vasculature for diagnosis and drug delivery. J Transl Med 10 (Suppl 1): S1, 2012.

21. Brown KC: Peptidic tumor targeting agents: The road from phage display peptide selections to clinical applications. Curr Pharm Des 16: 1040-1054, 2010.

22. Parks SK, Cormerais Y, Marchiq I and Pouyssegur J: Hypoxia optimises tumour growth by controlling nutrient import and acidic metabolite export. Mol Aspects Med 47-48: 3-14, 2016.

23. Wahba HA and El-Hadaad HA: Current approaches in treatment of triple-negative breast cancer. Cancer Biol Med 12: 106-116, 2015.

24. Bose S: Triple-negative breast carcinoma: Morphologic and molecular subtypes. Adv Anat Pathol 22: 306-313, 2015.

25. Noren KA and Noren CJ: Construction of high-complexity combinatorial phage display peptide libraries. Methods 23: 169-178, 2001.

26. Ahn KY, Ko HK, Lee BR, Lee EJ, Lee JH, Byun Y, Kwon IC, $\mathrm{Kim} \mathrm{K}$ and Lee J: Engineered protein nanoparticles for in vivo tumor detection. Biomaterials 35: 6422-6429, 2014. 